\title{
Concepção dos pescadores artesanais que utilizam o reservatório de Furnas, Estado de Minas Gerais, acerca dos recursos pesqueiros: um estudo etnoictiológico
}

\author{
Valter Monteiro de Azevedo-Santos ${ }^{1 *}$ \\ Eraldo Medeiros Costa-Neto ${ }^{2}$ \\ Nelci de Lima-Stripari ${ }^{1}$

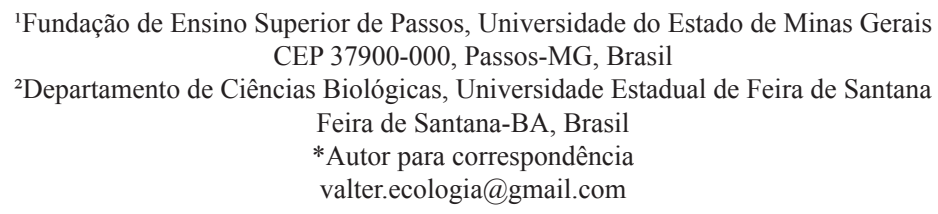

Submetido em 13/05/2010

Aceito para publicação em 23/09/2010

\section{Resumo}

A etnoictiologia, baseando-se em parâmetros da ecologia, pode ser uma ferramenta bastante útil no estudo das mudanças ambientais provocadas por ações humanas, pois tais mudanças são percebidas pelos sujeitos que exercem atividades pesqueiras de subsistência e/ou recreativas nos ambientes impactados. O objetivo do presente trabalho foi investigar as percepções dos pescadores artesanais do município de Carmo do Rio Claro, Minas Gerais, acerca das alterações decorrentes de ações antropogênicas. Os dados foram obtidos de agosto de 2009 a janeiro de 2010 por meio de entrevistas abertas e semi-estruturadas, recorrendo-se às técnicas usuais de registro etnográfico. Foram entrevistados 50 pescadores profissionais registrados, sendo 49 homens e apenas uma mulher. Os resultados revelam que esses pescadores têm observado a diminuição dos recursos pesqueiros, o desaparecimento e/ou escassez de algumas espécies e a introdução de espécies. Torna-se necessário procurar as melhores formas de recuperação e conservação das espécies nativas do reservatório de Furnas, além de um melhor monitoramento das espécies introduzidas.

Unitermos: Carmo do Rio Claro, etnoictiologia, etnozoologia, impactos antrópicos, pescadores artesanais, recursos pesqueiros, reservatório de Furnas

\section{Abstract}

Conception of the artisanal fisherfolk who use Furnas Reservoir, Minas Gerais State, about fishing stocks: an ethnoichthyological study. Ethnoichthyology, based on ecological parameters, can be a very useful tool to study man-made environmental changes. These changes are perceived by individuals who fish for a living and/or recreational activities in the impacted environs. The objective of this study was to investigate how the artisanal fisherfolk of the municipality of Carmo do Rio Claro, Minas Gerais, perceive the environmental changes caused by anthropogenic actions. The data were collected from August 2009 to January 2010 by means of openended interviews according to usual ethnographical techniques. Fifty professional fisherfolk were interviewed, forty-nine men and one woman. The results showed that they had experienced a reduction of fishing resources, 
the disappearance and/or rarity of some species, and the introduction of species. This pointed to the necessity of seeking the best ways to recover and conserve the native species of the Furnas Reservoir, in addition to a better monitoring of the introduced species.

Key words: anthropic impacts, artisanal fisherfolk, Carmo do Rio Claro, ethnoichthyology, ethnozoology, fishing resources, Furnas Reservoir

\section{Introdução}

Entre os enfoques com grande contribuição nos estudos do conhecimento de populações tradicionais sobre a Natureza está a etnociência, uma ferramenta de análise teórico-metodológica com origem em várias disciplinas, especialmente antropologia cognitiva e linguística, que estuda os conhecimentos humanos sobre os fenômenos naturais, procurando encontrar a coerência que está por trás do saber e do saber-fazer das comunidades sobre o mundo natural (Diegues, 1998; 2000).

Nesta área, destaca-se a etnobiologia, que é essencialmente o estudo do conhecimento e das conceituações desenvolvidas por qualquer sociedade a respeito da biologia (Posey, 1987), ou seja, a forma como indivíduos pertencentes a comunidades tradicionais, indígenas, locais ou mesmo urbano-rurais concebem, classificam e manejam os recursos naturais (Mourão e Nordi, 2002). Os estudos etnobiológicos têm sido cruciais para estabelecimentos de estratégias de importância para conservação do meio ambiente (Albuquerque, 1999; Adams, 2000), começando a exercer influência em políticas públicas de conservação e de cunho participativo (Diegues, 1999; Diegues e Arruda, 2001).

Dentro da etnobiologia, existe uma ramificação de campos definidos a partir da visão compartimentada da ciência sobre a natureza, como são a etnozoologia, etnobotânica, etnoecologia, etnofarmacologia, etnoentomologia, etc (Haverroth, 1997; Souza e Barrella, 2001). Na etnozoologia, ramo que estuda o conhecimento zoológico tradicional (Costa-Neto et al., 2009), está incluída uma diversidade de manifestações dos seres humanos frente à fauna existente (RochaMendes et al., 2005), o que tem levado os estudos nesta área a gerar respostas relacionadas com a forma como os seres humanas concebem, representam e se relacionam com os animais (Costa-Neto et al., 2009). Nesse campo, a maioria dos estudos está centrada nas subáreas da etnoornitologia e da etnoictiologia (Adams, 2000). Nesta última, estuda-se a inserção dos peixes em uma dada cultura (Posey, 1987), tratando do modo como grupos humanos interagem com os recursos ícticos (Silvano, 1997), tendo como objetivo buscar a compreensão dos fenômenos da interação entre humanos e peixes, o que engloba formas cognitivas e comportamentais (Marques, 1995).

A expressão etnoictiologia foi pela primeira vez empregada na literatura científica por Morrill (1967), que a incluiu em título do artigo. $\mathrm{O}$ autor justificou o termo afirmando que este teria surgido a partir do modelo de "etnobotânica" (Costa-Neto et al., 2002; Mourão e Nordi, 2002; 2003). Desde então, este termo tem obtido sucesso que se expressa pela quantidade de trabalhos que o empregam.

A etnoictiologia, baseando-se em parâmetros da ecologia, pode ser uma ferramenta bastante útil no estudo das mudanças ambientais provocadas por fatores antropogênicos, tais como: a diminuição dos estoques pesqueiros (Paiola e Tomanik, 2002; Gerhardinger et al., 2006); o desaparecimento de espécies de peixes (Pinheiro, 2004); e a inserção de novas espécies (exóticas e/ou alóctones) em determinados ambientes (Carvalho, 2002; Pinheiro, 2004; Moura e Marques, 2007; Moura et al., 2008). Tais mudanças são percebidas pelos sujeitos que exercem atividades pesqueiras de subsistência elou recreativas nos ambientes impactados. Isso demonstra que os pescadores não dominam apenas conhecimentos referentes à etnotaxonomia, aspectos comportamentais e preferências alimentares, por exemplo, (Costa-Neto e Marques, 2000a), como também possuem uma visão mais ampla do que vem ocorrendo com o meio ambiente do qual dependem para diversos fins. Consequentemente, os pescadores podem fornecer um conjunto valioso de informações de como manejar, conservar e utilizar a fauna íctica e o meio ambiente (Costa-Neto e Marques, 2000a). 
O objetivo do presente trabalho foi realizar um estudo etnoictiológico, no município de Carmo do Rio Claro-MG, investigando as percepções dos pescadores artesanais do município acerca das alterações decorrentes de ações antropogênicas, como: diminuição dos estoques pesqueiros; desaparecimento de espécies de peixes; e introdução de novas espécies.

\section{Material e Métodos}

\section{Área de estudo}

As pesquisas foram realizadas na cidade de Carmo do Rio Claro (205'23'S, 4607'08'W) (Figura 1), localizada na região sudoeste do Estado de Minas Gerais. Com população estimada em julho de 2009 de 20070 habitantes (IBGE, 2009), o município limita-se com Alfenas, Alterosa, Alpinópolis, Boa Esperança, Campo do Meio, Campos Gerais, Conceição da Aparecida, Guapé, Ilicínea, Nova Resende e São José da Barra. Seu clima é seco e temperado; tropical chuvoso com inverno seco. A temperatura média anual é de $26^{\circ} \mathrm{C}$; a máxima pode atingir os $38^{\circ} \mathrm{C}$ e a mínima, $8^{\circ} \mathrm{C}$. A vegetação característica do município é a de transição de Mata Atlântica para o Cerrado. Sua bacia hidrográfica resulta em centenas de nascentes, que brotam das serras e dão origem a vários riachos e córregos que banham o município. São muitas as montanhas que compõem o relevo carmelitano. As principais são: Serra do Tabuleiro com 1.304m; Serra da Tormenta, com 1.287m; e Pico São Gabriel, com 1.197m (Horváth, 2007).

A partir de 1962, a hidrografia da região sofreu uma série de modificações. O Rio Grande e seus afluentes inundaram onze mil alqueires de terras agricultáveis, formando o reservatório de Furnas (Horváth, 2007; Azevedo-Santos e Lima-Stripari, 2010). Considerado por muitos como o "Mar de Minas", o Lago de Furnas é a maior extensão de água da região sudeste do país (Landa et al., 2002) e, acredita-se, que também seja um dos maiores lagos artificiais do mundo. Cobrindo ao todo uma superfície aproximada de $1.406,26 \mathrm{~km}^{2}$, ele foi criado com o objetivo de geração de energia elétrica

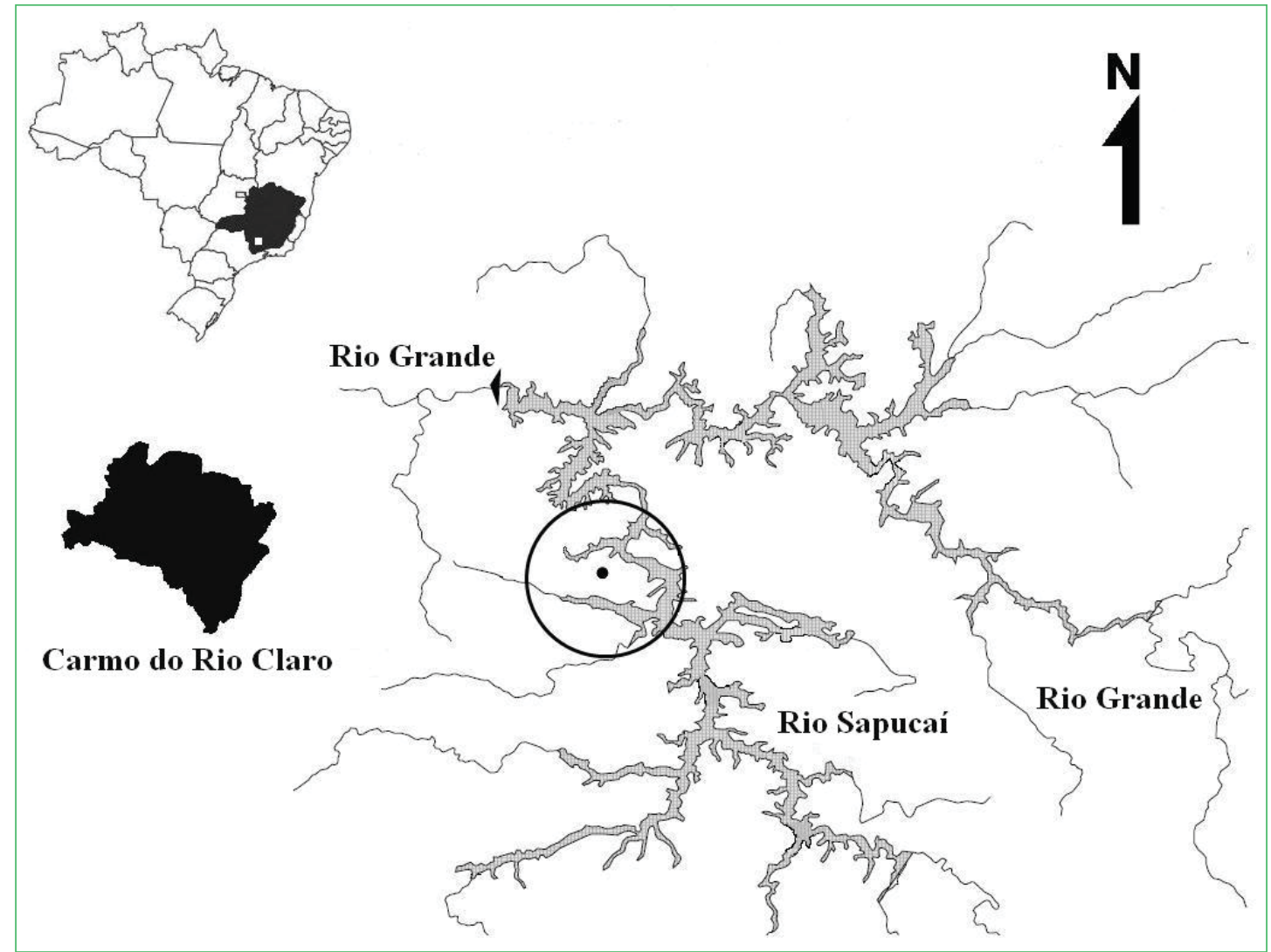

FIGURA 1: Região de estudo - localização do município de Carmo do Rio Claro e do reservatório de Furnas em Minas Gerais. 
com capacidade de gerar $1.216 \mathrm{~mW}$ de potência. O lago também é muito importante para o abastecimento de água das cidades no seu entorno.

Durante a construção da hidrelétrica, muitos moradores tiveram que abandonar suas casas, isso devido à grande faixa das terras que seriam inevitavelmente encobertas pelas águas. Por outro lado, o lago foi benéfico, pois foi graças a ele que mais pessoas passaram a viver inteiramente da pesca, direta ou indiretamente. Antes da inundação, os pescadores do município de Carmo do Rio Claro extraíam os peixes do Rio Sapucaí - cujo nome faz alusão à presença numerosa de uma árvore designada popularmente como "sapucaia". Os pescadores produziam suas próprias redes e também usavam covos de própria fabricação. Naquele tempo, muitos pescadores também eram caçadores, pois a caça era uma prática liberada. Carregavam suas armas nos seus barcos e abatiam todo tipo de animal que viam, inclusive peixes, que eram vendidos ou consumidos pelos próprios pescadores. A arma era embarcada também por motivos de segurança do "desconhecido", como o Nego d’Água, um ser mítico que segundo a crendice popular era o responsável por virar canoas e tomar os peixes dos pescadores.

Atualmente, a pesca no município modernizou-se, mas os pescadores ainda continuam sendo tradicionais, as redes são confeccionadas em fábricas e todos os pescadores são cadastrados em uma colônia de pesca. Em épocas de piracema (momento em que ocorre a desova dos peixes) os pescadores cadastrados recebem pelo tempo que ficam inativos, sendo que o período em que eles são assegurados vai do dia primeiro de novembro até o dia primeiro de março; durante esse tempo é proibida radicalmente a pesca com rede. Entretanto, no lago a pesca ainda pode continuar sendo exercida neste período, isso se utilizada apenas varas de mão, e mesmo assim com algumas restrições.

\section{Metodologia}

Os dados foram obtidos no período de agosto de 2009 a janeiro de 2010. O levantamento de informações dos pescadores artesanais que residem no município foi feito mediante realização de entrevistas abertas e semi-estruturadas para que pudessem ser acrescentados tópicos durante as entrevistas, adequando-se às necessidades do entrevistador (Rodrigues, 2009). As entrevistas foram efetuadas seguindo-se a abordagem etnocientífica, com enfoque emicista-eticista balanceado (Sturtevant, 1964). Nesta abordagem é registrada a forma em que ocorrem a percepção, categorização e interação dos moradores locais com os elementos faunísticos com os quais convivem, sem que o pesquisador imponha suas categorias (Costa-Neto, 2007).

As entrevistas ocorreram de modo individual para que não houvesse influência de informações (respostas) de um pescador para outro. Os pescadores entrevistados foram escolhidos de acordo com os seguintes critérios: pescadores profissionais registrados que vivem integralmente da pesca com no mínimo sete anos de atuação e pescadores aposentados, que ainda pescam para consumo doméstico ou eventual comércio. Foram entrevistadas 50 pessoas sendo 49 homens e apenas uma mulher. $\mathrm{O}$ tempo de profissão dos informantes varia entre sete a 50 anos. De maneira precisa e clara, os objetivos da pesquisa eram sempre explicados no começo de cada nova entrevista, perguntando se havia consentimento por parte deles (pescadores) em conceder informações (Costa-Neto, 2006; 2007), também para evitar que possivelmente alguns achassem que o trabalho se tratava de uma sindicância por parte de algum órgão de fiscalização ambiental.

Os dados obtidos foram analisados seguindo o modelo de união das diversas competências individuais de Hays (apud Marques, 1991), consistindo em levar em consideração todas as informações obtidas, sem exclusão, de todos os entrevistados. Este modelo tem sido muito utilizado em trabalhos de cunho etnocientíficos (Marques, 1991), tratando-se de uma analise quali-quantitativa.

Algumas das espécies foram coletadas e fornecidas pelos próprios pescadores informantes. Alguns dos entrevistados forneceram fotografias de espécies que desapareceram do lago ou ficaram raras de serem encontradas. As cópias das fotos, as entrevistas e os espécimes podem ser encontrados no Laboratório de Zoologia da UEMG campus de Passos. 
A identificação das espécies foi realizada pela bióloga Sumaya Cardoso de Castro. A abreviatura "ppr" encontrada no texto significa "pescador profissional registrado", seguido pelo tempo de registro.

\section{Resultados e Discussão}

Os dados aqui registrados referem-se a percepções dos pescadores posteriormente à construção da hidrelétrica de Furnas.

Os entrevistados citaram as seguintes espécies "nativas" (autóctones): traíra (Hoplias malabaricus) (86\% de citação), mandi (Pimelodus maculatus) (78\%), lambari-do-rabo-vermelho (Astyanax fasciatus) (54\%), lambari-do-rabo-amarelo (Astyanax altiparanae) (54\%), curimba (Prochilodus lineatus) (50\%), dourado (Salminus brasiliensis) (50\%), tabarana (Salminus hilarii) (28\%), piau-três-pintas (Leporinus friderici) (24\%), capineiro (Schizodon nasutus) (22\%), cigarra (Galeocharax knerii) (14\%), jaú (Zungaro jahu) (12\%), cará (Geophagus brasiliensis) (10\%), bagre (Rhamdia quelen) (8\%), saguiru (Cyphocharax nagelii) (8\%) e cascudo (Hypostomus regani) (6\%).

Todos os pescadores entrevistados afirmaram que houve uma diminuição dos recursos pesqueiros locais. A quantidade pescada no reservatório de Furnas, quando eles iniciaram a profissão de pescador com carteira (registro) e/ou começaram a pescar (pois muitos já pescavam bem antes de serem registrados), era bem maior que na atualidade. Disseram que se capturava em média $37 \mathrm{~kg}$ de peixe por dia. Antes, as redes eram visitadas duas vezes por dia, pois a quantidade de pescado era tão grande que os peixes poderiam apodrecer presos nas redes devido a fatores do ambiente, como a temperatura. Segundo um entrevistado: "Quem tinha dez panos de rede tinha o sustento tranquilo da família" e segundo o mesmo "atualmente um pescador trabalha com 30 a 40 panos de rede pra pegá a mesma quantidade, isso se não pegá menos" (ppr 23 anos). Outro entrevistado diz que chegava a capturar cerca de " $35 \mathrm{~kg}$ com pouca rede", e que "na época tinha muito peixe", acrescentando "se naquela época eu usasse o tanto de rede que eu uso hoje, eu ia pegá muito peixe" (ppr 20 anos).
Atualmente, captura-se em média apenas $13,3 \mathrm{~kg}$ por dia. Segundo um entrevistado, no ritmo que a pesca artesanal está, o pescador profissional já não terá, em um futuro próximo, condições de sobrevivência por parte de seu oficio.

Devido à percepção da queda de produção, foi perguntado aos entrevistados o que poderia estar causando essa diminuição. Cerca de 34\% deles informaram que o motivo da diminuição do pescado capturado se deve aos esgotos in natura que são lançados diretamente na água. Grande parte das cidades do entorno do reservatório de Furnas, inclusive Carmo do Rio Claro, deságuam seus esgotos direto no lago, sendo poucas as cidades do entorno que têm estação de tratamento de efluentes. Este é um problema em todo o Brasil, pois grande parte dos esgotos no país é lançada, sem tratamento prévio, em corpos d'água (Moreno e Callisto, 2004). Os efluentes de cidades sendo lançado em lagos foi apontado, também, por pescadores do Estado do Rio Grande do Sul como sendo uma causa que contribui para a diminuição da quantidade de pescado (Garcez e Sánchez-Botero, 2005).

Os entrevistados mencionam o aumento de casas construídas na beira do Lago de Furnas, que também deságuam seus esgotos. Alguns pescadores citam a dificuldade da pesca em locais onde há esse desaguamento, pois "pescar onde tem esgoto sendo lançado é impossível” (ppr 21 anos), onde deságua “o corgo da Barra é tão prejudicado que lá nem se pesca." (ppr 29 anos). Nesse trecho do Lago de Furnas, onde deságua o esgoto de Carmo do Rio Claro, conhecido como "corgo da Barra", segundo os pescadores, quase não existem mais peixes.

A percepção apontada pelos pescadores possivelmente pode estar contribuindo com a diminuição dos recursos pesqueiros, pois as substâncias que são constantemente despejadas nos ambientes aquáticos, principalmente de reservatórios (Baptista e Araujo Neto, 1994), são ricas em nutrientes, o que pode gerar eutrofização artificial (Rocha e Branco, 1986; Esteves, 1998; Tundisi, 2005; Tundisi et al., 2006). Este tipo de eutrofização consiste em um processo dinâmico, onde ocorrem profundas modificações qualitativas e quantitativas nas comunidades aquáticas, nas condições 
físicas e químicas do ambiente e no nível de produção do sistema (Esteves 1998; Loures et al., 2006). Um dos problemas mais preocupantes e principais é a proliferação de cianobactérias em detrimento de outras espécies aquáticas. Muitos gêneros de cianobactérias produzem toxinas que chegam a ser fatal, principalmente, para os peixes (Figueiredo et al., 2007). A eutrofização chega a ser considerada uma das principais causas da perda da biodiversidade aquática (Agostinho et al., 2005).

A segunda percepção, citada por $22 \%$ dos pescadores, é o aumento de pessoas que vivem da pesca ou que pescam, o que é muito significativo e talvez um fator que interfira na quantidade dos recursos ícticos. Houve um aumento muito relevante no número de indivíduos pescando e, consequentemente, o número de redes sendo colocadas também aumentou. Além dos pescadores que são registrados, existe uma alta quantidade de pessoas que pesca profissionalmente sem registro, mas esses indivíduos se limitam apenas em pescar com varas e molinetes, pois o uso de redes só é permitido, legalmente, para o profissional registrado.

A terceira percepção, citada por $44 \%$ dos informantes, é a de que a diminuição dos recursos está associada diretamente a agrotóxicos que são aplicados dentro da terra para matar cigarras e outras pragas de lavouras e que, ao chover, ocorre à lixiviação destes agrotóxicos para o lago, matando em grande quantidade os peixes. Cerca de $4 \%$ do percentual total disseram que antigamente alguns agricultores lavavam as bombas de veneno dentro da água e que isso matava os "menorzinho" (juvenis) de espécies devido ao fato destes ficarem nas encostas. De acordo com um dos pescadores, o mais utilizado e comum em várias plantações da região é o Baysiston, podendo encontrar outros tipos de agrotóxicos usados também para matar pragas em lavouras de batata e de café.

Nogueira et al. (2008), em estudo realizado, apontaram que os peixes do reservatório da Usina Hidrelétrica (UHE) de Furnas vêm sofrendo uma exposição e, consequentemente, estão respondendo aos efeitos de agentes tóxicos presentes na água e sedimento. Os agrotóxicos empregados em lavouras implicam em vários problemas que estão relacionados à contaminação ambiental, incluída, principalmente, a contaminação de corpos d'água (Krüger, 2009). Além de provocar um conjunto de alterações morfo-fisiológicas e metabólicas nos peixes (Barton e Iwama, 1991), podem ainda matálos (Kohler, 2003), pois estes são sensíveis a agentes tóxicos (Lupi et al., 2007). Assim, no caso do lago em questão, a explicação dada pelos informantes encontra sólido respaldo do que já se conhece sobre impactos de poluentes diversos sobre peixes.

\section{Desaparecimento de espécies}

Segundo os entrevistados, de todas as 15 espécies autóctones citadas, três já desapareceram do lago, como a curimba, citada por $80 \%$ dos pescadores como espécie que desapareceu, seguida pelo dourado (48\%) e jaú (36\%). Já $10 \%$ dos informantes afirmam que o dourado não desapareceu por completo, assim como outros $10 \%$ dizem o mesmo com relação à curimba, pois, segundo eles, tais espécies apenas se tornaram "raras", isto é, escassas. Todas as espécies citadas como desaparecidas ou escassas pelos informantes são peixes de "tempo das águas" (reofilicas), ou seja, que necessitam de águas correntes para migrarem e completarem seu ciclo reprodutivo:

"Jaú é um que nem vê mais. Tem também a curimba" (ppr 21 anos)

"Um peixe que sumiu mesmo foi o dourado" (ppr oito anos)

"No geral, os que sumiram é peixe de rio" (ppr 26 anos)

"Do tempo do rio pra cá foi desaparecendo uma porção de espécie. Tem umas que é de corredeira que não se vê mais, como o dourado" (ppr, 50 anos).

Esta última citação de um pescador que chegou a pescar no Rio Grande e também no seu afluente Sapucaí, antes da construção da barragem de Furnas, demonstra que o desaparecimento ou escassez dessas espécies, possivelmente, está intimamente relacionado à construção da Usina Hidrelétrica, além dos outros fatores antrópicos já levantados. As barragens são consideradas bloqueios intransponíveis na rota migratória de peixes de piracema, que são os mais valiosos do ponto de vista pesqueiro, comprometendo sua reprodução (Agostinho et al., 1992; Petrere Júnior, 1996; Godinho e Godinho, 
2003). A construção de reservatórios é, em geral, reconhecida como uma das formas mais agravantes em termos de degradação do habitat de águas interiores (Godinho e Godinho, 2003).

Provavelmente, essas espécies citadas estão a caminho da extinção no Lago de Furnas, pois existe uma dificuldade em manter populações das mesmas em rios barrados, principalmente o jaú, espécie que, inclusive, já está incluída na lista oficial do Estado de Minas Gerais e no Livro Vermelho das espécies ameaçadas (Machado et al., 1998).

\section{Espécies introduzidas}

Oito espécies foram citadas pelos pescadores entrevistados como introduzidas. O tucunaré (Cichla monoculus), uma das espécies citadas por $54 \%$ dos pescadores, é um predador e pode se alimentar de "filhotes" (juvenis) de outras espécies que poderiam alcançar grande porte (Rabelo e Araújo-Lima, 2002) e, consequentemente, de alto valor comercial na região de estudo. Segundo $24 \%$ dos pescadores, a predação de juvenis pelo tucunaré pode ser mais uma hipótese para explicar a diminuição dos estoques pesqueiros no reservatório de Furnas:

"Na cadeia alimentar da nossa represa ele tá no topo. Ele não tem o predador natural dele" (ppr, 23 anos).

"Ele não come pra matá a fome. Ele come por causa do movimento mesmo" (ppr, 21 anos).

O aparecimento de espécies piscívoras, como é o caso do tucunaré no Lago de Furnas, pode conduzir ao declínio das populações ícticas locais (Agostinho e Julio Jr, 1996; Petrere Júnior, 1989; Alves e Vono, 1997; Santos et al., 2001; Gomiero e Braga, 2003). No lago, o tucunaré é pescado com iscas vivas ou artificiais; segundo um dos pescadores, é o peixe mais comum de ser capturado durante o dia com anzóis, pois não costuma "entrar nas redes".

Cerca de $80 \%$ dos pescadores se referem a uma etnoespécie conhecida por eles como "cdzinho" (Metynnis maculatus). Esse peixe é conhecido popularmente, em outras regiões, como "pacu-peva", comum no Rio
Paraguai e na bacia do Rio Amazonas (Lacerda et al., 2003; Sabrina et al., 2009). Segundo os pescadores, essa espécie já está sendo muito capturada em suas redes e tem se transformado em um atraso na atividade pesqueira devido à grande quantidade de indivíduos capturados:

"Esse peixe virou praga aqui na represa" (ppr, 25 anos).

"Com malha 4 você não dá conta de tirar" (ppr, 28 anos).

“É um peixe que não cresce. Só fica pequeno e num serve nem pra vendê. A carne é muito ruim" (ppr, 27 anos).

"O cdzinho apareceu e rapidinho poluiu a água" (ppr, 21 anos).

Essa espécie foi introduzida no lago para minimizar os impactos causados pelo tucunaré nas espécies autóctones, no entanto, segundo um pescador, ele vai ser responsável por impulsionar ainda mais o declínio nos recursos pesqueiros. Para este pescador, o cdzinho é considerado uma espécie invasora que ameaça a biodiversidade local (Ziller et al., 2007), acrescentando que essa espécie "come as ovas de todos os peixes" (ppr, 20 anos). Isso demonstra que espécies alóctones, aquelas que são introduzidas em outras áreas de seu continente ou país de origem (Shafland e Lewis, 1984; Fuller et al., 1999; Agostinho et al., 2000; Richardson et al., 2000; Agostinho et al., 2006), são tão ameaçadoras quanto as espécies exóticas.

Outra espécie citada por $44 \%$ dos informantes foi o bagre-africano (Clarias gariepinus), que vem sendo pego por eles nas redes já há aproximadamente 15 anos: "Esse peixe costuma aparecer quando a água abaixa, pega muito dele" (ppr, sete anos); "Rasga tudo as rede" (ppr, 27 anos). Este peixe é proveniente da África (Vidotti et al., 2000), com distribuição ampla no continente, porém, pode ocorrer ainda em partes da Ásia, como Israel, Síria e sul da Turquia (De Graaf e Janssen, 1996).

A carpa (Cyprinus carpio) foi citada por 10\% dos pescadores como uma espécie que tem sido percebida no Lago de Furnas. As carpas são de origem asiática, onde já eram criadas na China há mais de 2.000 anos. Ela marcou o início da piscicultura no continente europeu 
no começo da Idade Média, em criações desenvolvidas em conventos pela necessidade dos monges em obter peixes frescos (Echevenguá et al., 2007). Estão entre as espécies amplamente utilizadas pela piscicultura porque se caracterizam por sua extrema rusticidade e excelente desempenho (Hajra, 1987). No Brasil, as carpas foram introduzidas no Estado de São Paulo em 1904, sendo que as criações intensivas só tiveram início na década de 1930 (Galli e Torloni, 1986).

Alguns entrevistados mencionam estar capturando, também, espécies como jeju (Hoplerythrinus unitaeniatus), citada por $30 \%$, e caborja (Hoplosternum littorale), citada por $44 \%$ dos respondentes. São espécies comuns no Brasil, porém no lago elas são consideradas alóctones. É um peixe "babento", "num morre fácil dentro da canoa", dizem pescadores se referindo ao jeju. "Aquele bicho faz uma barulheira", disse pescador se referindo ao caborja. Costa-Neto e Marques (2000b) em trabalho realizado, relatam o fenômeno etológico de peixes que produzem som, denominado pelos pescadores artesanais de Siribinha como: "peixes que fazem zoada".

A tilápia-do-nilo (Oreochromis niloticus), citada por $34 \%$, e a tilápia-capim (Tilapia rendalli), citada por 20\%, são naturais da África, de Israel e da Jordânia (Hayashi et al., 1999; Hermes et al., 2005), no entanto, são os peixes que têm grande valor comercial na região. Segundo um entrevistado, a tilápia-capim foi uma das primeiras espécies a ser introduzida no lago, na década de 1970. Quando foi descoberta no lago era reconhecida como "praga", pois a comunidade de pescadores não sabia que era um peixe de bom valor comercial, retirando-as de suas redes, matando-as e jogando nas encostas. Atualmente, "ela é o ganha pão do pessoal" (ppr, 27 anos). Logo depois, houve a percepção do aparecimento da tilápia-do-Nilo em meados da década de 1990. Mesmo que a inserção de algumas espécies traga benefícios econômicos, o que é o caso das tilápias no Lago de Furnas, por outro lado é importante levar em consideração que espécies introduzidas podem trazer problemas para comunidades autóctones, tais como: hibridização, perda do patrimônio genético original, alterações tróficas e introdução de doenças e parasitas (Taylor et al., 1984; Magalhães, 2006) o que implica, assim como a predação, na diminuição de espécies.
Os entrevistados demonstraram percepções importantes das mudanças que estão ocorrendo no reservatório de Furnas. Mediante os resultados obtidos, constata-se que é necessário intensificar estudos buscando formas de recuperação e conservação da íctiofauna autóctone da região. Além disso, sugeri-se de imediato um melhor monitoramento das espécies que já foram introduzidas e criar medidas para evitar novas introduções.

\section{Agradecimentos}

A todos os pescadores que participaram, principalmente ao pescador Claudio Giovane Lopes pelo fornecimento de espécies. A bióloga Sumaya Cardoso de Castro pela identificação das espécies ao Dr. Flávio César Thadeo de Lima, do Museu de Zoologia da USP, pelas ajudas taxonômicas prestadas.

\section{Referências}

Adams, C. 2000 Caiçaras na mata Atlântica: pesquisa versus planejamento e Gestão ambiental. Editora Annablume, São Paulo, Brasil, 337pp.

Agostinho, A. A.; Julio Jr., H. F. 1996. Peixes de outras águas. Rio de Janeiro. Ciência Hoje, 21 (124): 36-44.

Agostinho, A. A.; Julio Jr., H. F.; Borghetti, J. R. 1992. Considerações sobre os impactos dos represamentos na ictiofauna e medidas para sua atenuação um estudo de caso: reservatório de Itaipu. Revista Unimar, 14: 89-107.

Agostinho, A. A.; Julio Jr., H. F.; Torloni, C. E. 2000. Impactos causados pela introdução e transferência de espécies aquáticas: uma síntese. Anais VII Simpósio Brasileiro de Aqüicultura, Piracicaba, Brasil, p.56-75.

Agostinho, A. A.; Pelicice, F. M.; Julio Jr., H. F. 2006. Biodiversidade e introdução de espécies de peixes: unidades de conservação. In: Campos, J. B.; Tossulino, M. G. P. \& Muller, C. R. C. (Org). Unidades de conservação - Ações para valorização da biodiversidade. Instituto Ambiental do Paraná, Curitiba, Brasil, p.95-117.

Agostinho, A. A.; Thomaz, S. M.; Gomes, L. C. 2005. Conservação da biodiversidade em águas continentais do Brasil. Megadiversidade, 1 (1): 70-78

Albuquerque, U. P. 1999. La importancia de los estudios etnobiológicos para establecimiento de estrategias de manejo y conservación en las florestas tropicales. Biotemas, 12: 31-47.

Alves, C. B. M.; Vono, V. 1997. O caminho da sobrevivência para os peixes do rio Paraopeba. Rio de Janeiro. Ciência Hoje, 21 (126): 14-16. 
Azevedo-Santos, V.M.; Lima-Stripari, N. 2010. Primeiro registro de Dilocarcinus pagei Stimpson, 1861 (Decapoda, Trichodactylidae) no estado de Minas Gerais. Biotemas, 23 (2): 199-202.

Baptista, G. M. M.; Araujo Neto, M. D. 1994. O Processo de Eutrofização Artificial no Lago Paranoá. Geonomos, 2 (2): 31-39.

Barton, B. A.; Iwama, G. K. 1991. Physiological changes in fishes from stress in aquaculture with emphasis on the response and effects of corticosteroids. Annual Review of Fishes Diseases, 10: 3-26.

Carvalho, A. R. 2002. Conhecimento ecológico no ‘varjão' do alto rio Paraná: alterações antropogênicas expressas na linguagem dos pescadores. Acta Scientiarum, 24 (2): 581-589.

Costa-Neto, E. M. 2006. "Piolho-de-cobra" (Arthropoda: Chilopoda: Geophilomorpha) na concepção dos moradores de Pedra Branca, Santa Terezinha, Estado da Bahia, Brasil. Acta Scientiarum Biological Science, 28 (2): 143-148.

Costa-Neto, E. M. 2007. O caranguejo-de-água-doce, Trichodactylus fluviatilis (Latreille, 1828) (Crustacea, Decapoda, Trichodactylidae), na concepção dos moradores do povoado de Pedra Branca, Bahia, Brasil. Biotemas, 20 (1): 59-68.

Costa-Neto, E. M; Dias, C. V; Melo, M. N. 2002. O conhecimento ictiológico tradicional dos pescadores da cidade de Barra, região do médio São Francisco, Estado da Bahia, Brasil. Acta Scientiarum, 24 (2): 561-572.

Costa-Neto, E. M.; Marques, J. G. W. 2000a. A Etnotaxonomia de recursos ictiofaunísticos pelos pescadores da comunidade de Siribinha, Norte do Estado da Bahia, Brasil. Biociências, 8 (2): 61-76.

Costa-Neto, E. M.; Marques, J. G. W. 2000b. Etnoictiologia dos pescadores artesanais de Siribinha, município de Conde (Bahia): aspectos relacionados com a etologia dos peixes. Acta Scientiarum, 22 (2): 553-560.

Costa-Neto, E. M.; Vargas-Clavijo, M.; Santos-Fita, D. 2009. Manual de Etnozoología: una guía teórico-práctica para investigar la interconexión del ser humano con los animales. Tundra Ediciones, Valencia, España, p.15-20.

De Graaf, G.; Janssen, H. 1996. Artificial reproduction and pond rearing of the African catfish Clarias gariepinus in sub-Saharan África - a handbook. v.362. FAO Fisheries Technical Paper, Rome, Italy, 73pp.

Diegues, A. C. 1998 O mito moderno da natureza intocada. HUCITEC, São Paulo, Brasil, 169pp.

Diegues, A. C. 1999. A construção de uma nova ciência da conservação para as áreas protegidas nos trópicos: a etnoconservação. Debates Socioambientais, 5 (13): 9-11.

Diegues, A. C. 2000. Etnoconservação da natureza: enfoques alternativos. In: Diegues, A. C. (Org.). Etnoconservação - Novos rumos para a conservação da natureza. HUCITEC, São Paulo, Brasil, p.1-46.

Diegues, A. C. S.; Arruda, R. S. V. 2001. Saberes tradicionais e biodiversidade no Brasil. USP/NUPAUB/MMA, São Paulo, Brasil, 176pp.

Echevenguá, M. M.; Figueiredo, M. R. C.; Abdallah, P. R. 2007. Avaliação econômica de um policultivo de carpas chinesas por pequenos produtores rurais e pescadores artesanais de Rio Grande e São José do Norte - RS. Sinergia, 11(1): 9-16.

Esteves, F. A. 1998. Fundamentos de Limnologia. $2^{\text {a }}$ ed. Interciência, Rio de Janeiro, Brasil, 602 pp.
Figueiredo, M. C. B.; Teixeira, A. S.; Araújo, L. F. P.; Rosa, M. F.; Paulino, W. D.; Mota, S.; Araújo, J. C. 2007. Avaliação da vulnerabilidade ambiental de reservatórios à eutrofização. Engenharia Sanitária Ambiental, 12 (4): 399-409.

Fuller, P. L.; Nico, L. G.; Williams, J. D. 1999. Nonindigenous Fishes Introduced into Inland Waters of the United States. Special Publication 27. American Fisheries Society, Bethesda, USA, 613 pp.

Galli, L. F.; Torloni, C. E. 1986. Criação de peixes. $3^{\text {a }}$ ed. Nobel, São Paulo, Brasil, 119pp.

Garcez, D. S.; Sánchez-Botero, J. I. 2005. Comunidades de pescadores artesanais no Estado do Rio Grande do sul. Atlântica, 27 (1): 17-29.

Gerhardinger, L. C.; Marenzi, R. C.; Silva, M. H.; Medeiros, R. P. 2006. Conhecimento ecológico local de pescadores da Baía Babitonga, Santa Catarina, Brasil: peixes da família Serranidae e alterações no ambiente marinho. Acta Scientiarum Biological Sciences, 28 (3): 253-261.

Godinho, H. P.; Godinho, A. L. 2003. Breve visão do São Francisco. In. Godinho, H. P. \& Godinho, A. L. (Org.). Águas, peixes e pescadores do São Francisco das Minas Gerais. Editora PUC Minas, Belo Horizonte, Brasil, p.15-24.

Gomiero, L. M.; Braga, F. M. S. 2003. Pesca experimental do tucunaré, gênero Cichla (Osteichthyes Cichlidae), no reservatório

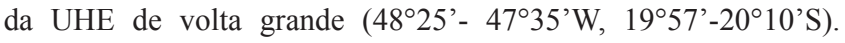
Boletim do Instituto de Pesca, 29 (1): 29-37.

Hajra, A. 1987. Biochemical investigations on the proteincalorie availability in grass carp (Ctenopharyngodon idella Val.) from an aquatic weed (Ceratophyllum demersum Linn.) in the tropics. Aquaculture, 61 (2): 113-120.

Haverroth, M. 1997. Etnobotânica: uma revisão teórica. Antropologia em primeira mão, 20: 1-56.

Hayashi, C.; Boscolo, W. R.; Soares, C. M.; Boscolo, V. R.; Galdioli, E. M. 1999. Uso de diferentes graus de moagem dos ingredientes em dietas para a tilápia-do-Nilo (Oreochromis niloticus L.) na fase de crescimento. Maringá. Acta Scientiarum, 21 (3): 733-737.

Hermes, C. A.; Souza, S. N. M.: Feiden, A.; Souza, J.; Bard, J.; Scheffer, J.; Engelmann, L. 2005. Compostagem como fonte térmica de energia para aquecimento de água na aqüicultura. Maringá. Acta Scientiarum Technology, 27 (2): 197-205.

Horváth, E. E. 2007. Carmo do Rio Claro/Cento e trinta anos de emancipação política. Editora Particular, Carmo do Rio Claro, Brasil, 15pp.

IBGE - Instituto Brasileiro de Geografia e Estatística. 2009. Estimativa das populações residentes, em $1^{\circ}$ de julho de 2009, segundo os municípios. Disponível em <http://www.ibge.gov.br/ home/estatistica/populacao/estimativa2009/POP2009_DOU.pdf>. Acesso em 30 de outubro de 2009.

Kohler, H. C. 2003. Aspectos geoecológicos da bacia hidrográfica do São Francisco (primeira aproximação na escala 1:1 000 000). In: Godinho H. P. \& Godinho A. L. (Ed.). Águas, peixes e pescadores do São Francisco das Minas Gerais. Editora PUC Minas, Belo Horizonte, Brasil, p.25-35.

Krüger, R. A. 2009. Análise da toxicidade e da genotoxicidade de agrotóxicos utilizados na agricultura utilizando bioensaios com Allium cepa. Dissertação de Mestrado, Universidade Feevale, Brasil. 58pp. 
Lacerda, A. C. F.; Takemoto, R. M.; Pavanelli G. C. 2003. A new species of Dadayius Fukui, 1929 (Digenea: Cladorchiidae), parasite of the intestinal tract of Metynnis maculatus (Kner, 1858) (Characidae) from the Upper Paraná River floodplain, Brazil. Acta Scientiarum Biological Sciences, 25: 283-285.

Landa, G. G.; Rull, L. M. A.; Pinto-Coelho, R. M. 2002. Distribuição espacial e temporal de Kellicottia bostoniensis (Rousselet, 1908) (Rotifera) em um grande reservatório tropical (reservatório de Furnas), Estado de Minas Gerais, Brasil. Acta Scientiarum Biological Sciences, 24 (2): 313-319.

Loures, A. P. S.; Soares, A. A.; Matos, A. T.; Cecon, P. R.; Pereira, O. G. 2006. Remoção de fósforo em sistema de tratamento de esgoto doméstico, por escoamento superficial. Revista Brasileira de Engenharia Agrícícola Ambiental, 10 (3): 706-714.

Lupi, C.; Nhacarini, N. I.; Mazon, A. F.; Rigolin-Sá, O. 2007. Avaliação da poluição ambiental através das alterações morfológicas nas brânquias de Oreochromis niloticus (tilapia) nos córregos Retiro consulta e Bebedouro, município de Bebedouro-SP. Revista Fafibe On Line, 3: 1-6.

Machado, A. B. M.; Fonseca G. A. B.; Machado, R. B.; Aguiar, L. M. S.; Lins, L. V. 1998. Livro vermelho das espécies ameaçadas de extinção da fauna de Minas Gerais. Fundação Biodiversitas, Belo Horizonte, Brasil, 605pp.

Magalhães, A. L. B. 2006. First record of lernaeosis in a native fish species from a natural environment in Minas Gerais state, Brazil. Pan-American Journal of Aquatic Sciences, 1 (1): 8-10.

Marques, J. G. W. 1991. Aspectos ecológicos na etnoictiologia dos pescadores do Complexo Estuarino-lagunar MundaúManguaba. Tese de Doutorado, Universidade Estadual de Campinas, Brasil, 293pp.

Marques, J. G. W. 1995. Etnoictiologia: pescando pescadores nas águas da transdisciplinaridade. Resumos do IV Encontro Brasileiro de Ictiologia, Campinas, Brasil, p.1-41.

Moreno, P.; Callisto, M. 2004. Bioindicadores de qualidade de água ao longo da bacia do Rio das Velhas. In: Ferracini, V. L.; Queiroz, S. C. N.; Silveira, M. P. (Ed.). Bioindicadores de Qualidade da Água. v.1. EMBRAPA, Jaguariúna, Brasil, p.95-116.

Morrill, W. T. 1967. Ethnoichthyology of the Cha-Cha. Ethnology, 6: 405-417.

Moura, F. B. P.; Marques, J. G. W. 2007. Conhecimento de pescadores tradicionais sobre a dinâmica espaço-temporalde recursos naturais na Chapada Diamantina, Bahia. Biota Neotropica, 7 (3): 119-126.

Moura, F. B. P.; Marques, J. G. W.; Nogueira, E. M. S. 2008. "Peixe sabido, que enxerga de longe": conhecimento ictiológico tradicional na Chapada Diamantina, Bahia. Biotemas, 21 (3): 115-123.

Mourão, J. S; Nordi, N. 2002. Principais critérios utilizados por pescadores artesanais na taxonomia folk dos peixes do estuário do Rio Mamanguape, Paraíba - Brasil. Interciencia, 27 (11): 607-612.

Mourão, J. S.; Nordi, N. 2003. Etnoictiologia de pescadores artesanais do estuário do rio Mamanguape, Paraíba, Brasil. Boletim do Instituto de Pesca, 29 (1): 9-17.

Nogueira, D. J.; Castro, S. C.; Rigolin-Sá, O. 2008. Avaliação da qualidade da água no reservatório UHE Furnas-MG, utilizando as brânquias de Pimelodus maculatus (LACÈPÉDE, 1803) como biomarcador de poluição ambiental. Ciência et Práxis, 1: 15-20.
Paiola, L. M; Tomanik, E. A. 2002. Populações tradicionais, representações sociais e preservação ambiental: um estudo sobre as perspectivas de continuidade da pesca artesanal em uma região ribeirinha do rio Paraná. Acta Scientiarum, 24 (1):175-180.

Petrere Júnior, M. 1989. River fisheries in Brazil: a review. Regulated rivers: research and management. v.4. John Wiley \& Sons Ltd, London, UK, p.1-16

Petrere Júnior, M. 1996 Fisheries in large tropical reservoirs in South America. Lakes \& Reservoirs: Research and Management, 2: 111-133.

Pinheiro, L. 2004. Da ictiologia ao etnoconhecimento: saberes populares, percepção ambiental e senso de conservação em comunidade ribeirinha do rio Piraí, Joinville, Estado de Santa Catarina. Maringá. Acta Scientiarum. Biological Sciences, 26 (3): 325-334.

Posey, D. A. 1987. Introdução: Etnobiologia: Teoria e Prática. In: Ribeiro, D. (Ed.). Suma Etnológica brasileira. v.1. Vozes/FINEP, Petrópolis, Brasil, p.15-25.

Rabelo, H.; Araújo-Lima, C. A. R. M. 2002. A dieta e o consumo diário de alimento de Cichla monoculus na Amazônia Central. Acta Amazônica, 32 (4): 707-724.

Richardson, D. M.; Pysek, P.; Rejmánek, M. G.; Barbour, F.; Panetta, D.; West, C. J. 2000. Naturalization and invasion of alien plants: concepts and definitions. Diversity and Distribution, 6: 93 107.

Rocha, A. A.; Branco, S. M. 1986. A eutrofização e suas implicações na ciclagem de nutrientes. Acta Limnológica Brasiliensia, 1: 201 242.

Rocha-Mendes, F.; Mikich, S. B.; Bianconi, G. V.; Pedro, W. A. 2005. Mamíferos do Município de fênix, Paraná, Brasil: etnozoologia e conservação. Revista Brasileira de Zoologia, 22 (4): 991-1002.

Rodrigues, A. S. 2009. Metodologia de la investigación Etnozoológica. In. Costa-Neto, E. M.; Vargas-Clavijo, M.; Santos - Fita, D. (Org.). Manual de Etnozoología: Una guía teóricopráctica para investigar la interconexión del ser humano con los animales. Tundra Ediciones, Valencia, España, p.253-272.

Sabrina, B.; Lopes, C. E.; Almeida-Toledo, L. F. 2009. Cytogenetic characterization of Metynnis maculatus (Teleostei; Characiformes): the description in Serrasalminae of a small B chromosome bearing inactive NOR-like sequences. Caryologia, 62 (2): 95-101.

Santos, L. N.; Gonzalez, A. F.; Araújo, F. G. 2001. Dieta do tucunaré amarelo Cichla monoculus (Bloch \& Schneider) (Osteichthyes, Cichlidae), no reservatório de Lajes, Rio de Janeiro, Brasil. Revista Brasileira de Zoologia, 18 (1): 191-204.

Shafland, P. L.; Lewis, W. M. 1984. Terminology associated with introduces organisms. Fisheries, 9: 17-18.

Silvano, R. A. M. 1997. Ecologia de três comunidades de pescadores do rio Piracicaba (SP). Dissertação de Mestrado, Universidade Estadual de Campinas, Brasil, 147pp.

Souza, M. R.; Barrella, W. 2001. Conhecimento popular sobre peixes numa comunidade caiçara da Estação Ecológica de Juréia Itatins/SP. Boletim do Instituto de Pesca, 27: 123-130.

Sturtevant, W. C. 1964. Studies in ethnoscience. American Anthropologist, 66 (3): 99-131. 
Taylor, J. N.; Courtenay Jr, W. R.; McCann, J. A. 1984. Known impacts of exotic fishes in the continental Unites States. In: Courtenay Jr., W. R. \& Stauffer Jr, J. R. (Eds). Distribution, biology and management of exotic fishes. John Hopkins University Press, Baltimore, USA, p.322-373.

Tundisi, J. G.; Matsumura Tundisi, T. M.; Galli, C. S. 2006. Eutrofização na América do Sul: causas, conseqüências e tecnologias para gerenciamento e controle. Editora Rima IIE, São Carlos, Brasil, 532pp.
Tundisi, J. G. 2005. Água no Século XXI: Enfrentando a escassez. $2^{\mathrm{a}}$ ed. Editora Rima IIE, São Carlos, Brasil, 256 pp.

Vidotti, R. M.; Carneiro, D. J.; Malheiros, E. B. 2000. Diferentes teores protéicos e de proteína de origem animal em dietas para o bagre africano, Clarias gariepinus (Burchell, 1822) na fase inicial. Acta Scientiarum, 22 (3): 717-723.

Ziller, S. R.; Zalba, S. M.; Zenni R. D. 2007. Modelo para o desenvolvimento de uma estratégia nacional para espécies exóticas invasoras. The Nature Conservancy/Gisp, Curitiba, Brasil, 61pp. 